\title{
A CASE REPORT OF MUCINOUS ADENOCARCINOMA COLON PRESENTING AS RIGHT GLUTEAL ABSCESS
}

Suresh Huchchannavar ${ }^{1}$

\section{HOW TO CITE THIS ARTICLE:}

Suresh Huchchannavar. "A Rare Case of Adeno Carcinoma Colon Presenting as Gluteal Abscess". Journal of Evolution of Medical and Dental Sciences 2015; Vol. 4, Issue 19, March 05; Page: 3386-3388,

DOI: $10.14260 /$ jemds/2015/488

ABSTRACT: Appendiceal cancer is rare; it accounts for only $0.5 \%$ of all gastrointestinal neoplasms. Further, mucinous adenocarcinoma (MA) of vermiform appendix is extremely rare, accounting only for $0.21 \%$ of all appendiceal malignancies. Here we are presenting a case of mucin secreting adeno carcinoma of colon which presented clinically as gluteal abscess.

KEYWORDS: Mucin secreting adeno carcinoma, carcinoma appendix, gluteal abscess.

CASE REPORT: A 65 year old female presented to surgery casualty at KIMS Hubli with a right gluteal swelling. It was associated with throbbing pain and fever. She also had pain right iliac fossa since 8 days. The patient had presented with similar complaints one month back to surgery casualty and diagnosed as gluteal abscess and treated surgically with incision and drainage. There were no other comorbidities or gynecological complaints.

On physical examination she was febrile. Tachycardia was present. There was tenderness in right iliac fossa with a globular mass of $6 \times 6 \mathrm{~cm}$. The borders were well defined with firm consistency, the surface was smooth, it was ballotable and was moving with respiration. There was a separate swelling in right gluteal region was present. Clinically a provisional diagnosis of appendicular mass with gluteal abscess was made.

On routine laboratory examination, her total count was 17,000cells/cumm other biochemical and hematological parameters were normal. Ultrasonography of abdomen showed a right iliac fossa collection of $4 \times 4 \mathrm{~cm}$ along with right gluteal abscess. Sonologically suspected as appendicular mass or ilio psoas abscess.

An MRI scan of abdomen is taken which showed chronic collection in right iliac fossa extending to iliopsoas muscle and sub cutaneous plane of right gluteal region. Possibly APPENDICULAR PERFORATION /ABSCESS formation with extension into iliopsoas and posterior cutaneous plane. 


\section{CASE REPORT}

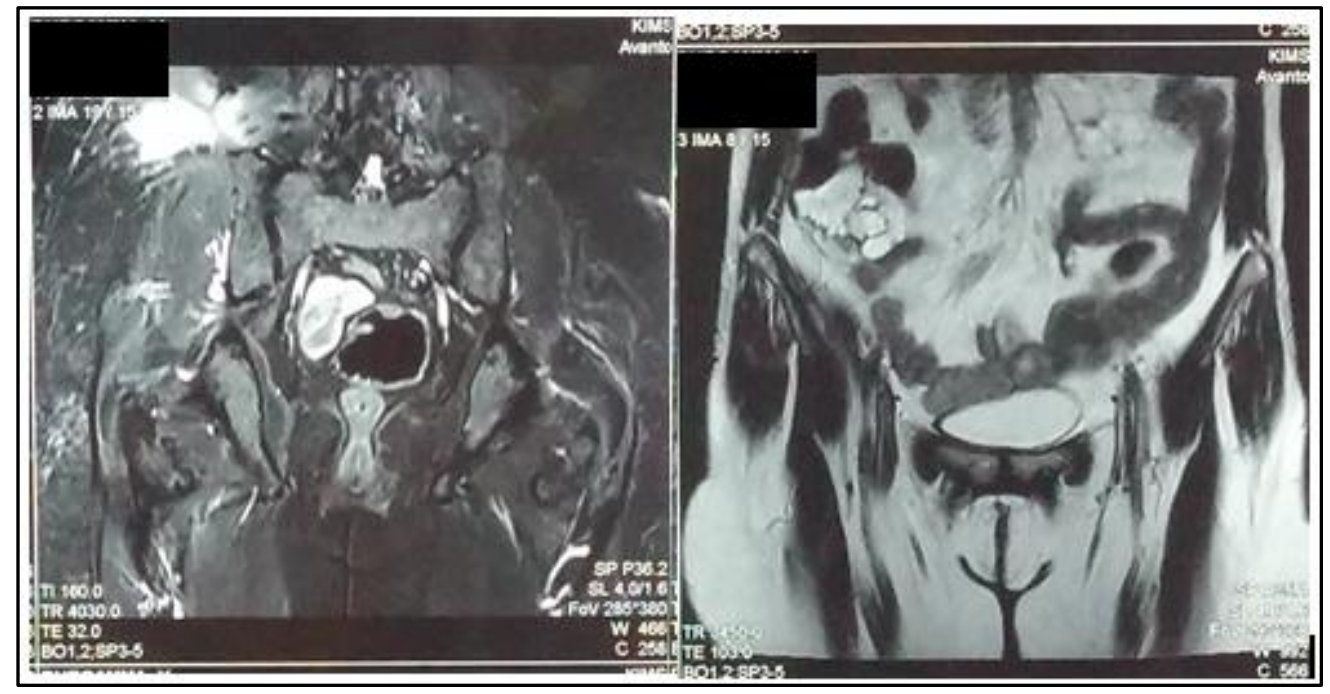

Fig. 1: MRI image showing collection in right iliac fossa with extension to ileopsoas

A decision for Laparotomy was made. Intra operatively it was found that a mass was present in caecal wall extending into peritoneum which contained gelatinous material. Caecum was adherent to the peritoneum. Multiple adhesions present involving small bowel and peritoneum. Right hemicolectomy was done.

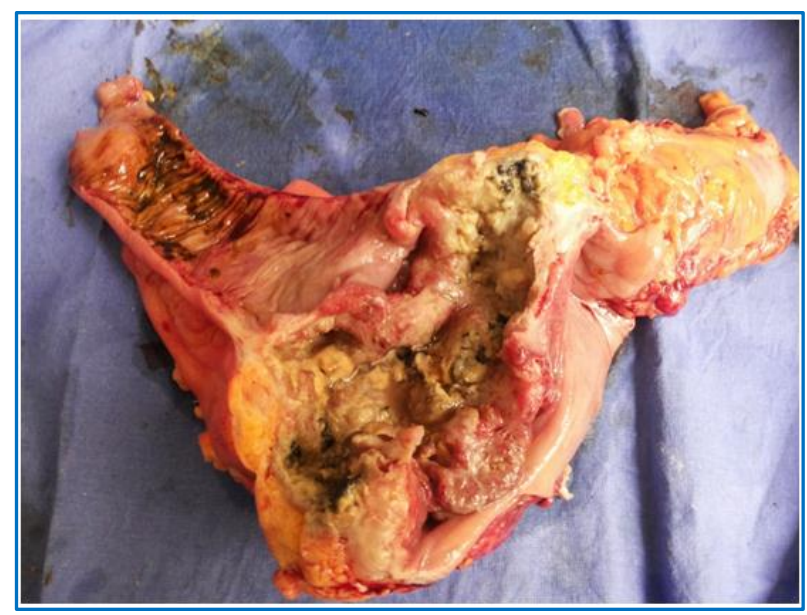

Fig. 2: The right hemicolectomy specimen

The Histopathology report has come as Mucin secreting adeno carcinoma extending up to the serosa at the ileocecal junction. The dissected lymph nodes showed only reactive changes. Clinical stage T4N0MO.

DISCUSSION: Appendiceal cancer is rare, it accounts for only $0.5 \%$ of all gastrointestinal neoplasms. ${ }^{1}$ According to a nationwide cancer database (SEER), the age-adjusted incidence of appendiceal 
malignancies was 0.12 case per 1,000,000 people per year. ${ }^{1}$ Primary appendiceal cancer is diagnosed in only $0.9 \%-1.4 \%$ of appendectomy specimens. Further, mucinous adenocarcinoma (MA) and signet-ring cell carcinoma (SRCC) of vermiform appendix are extremely rare, accounting only for $0.21 \%$ and $0.43 \%$ of all appendiceal malignancies. ${ }^{2}$

In the present case, primary Mucinous adeno carcinoma of the appendix clinically manifested as right iliac fossa mass with right gluteal abscess. The growth was attached to the parietal peritoneum and continued into the right iliac fossa as a globular mass. The same mass continued as the gluteal abscess. The slides from the tumor showed mucin secreting adeno carcinoma extending upto the serosa. The sections from adjacent lymphnodes showed reactive changes. This presentation is not documented anywhere in medical literature.

CONCLUSION: A rare clinical presentation of colonic carcinoma, clinically presented as appendicular mass with right gluteal abscess. It radiologically mimicked iliopsoas abscess.

\section{REFERENCES:}

1. M. E. McCuster, T. R. Cote, L. X. Clegg, L. H. Sobin Primary malignant neoplasms of the appendix: a population-based study from the surveillance, epidemiology and end-results program, 19731998.

2. M. E. O’Donnell, S. A. Badger, G. C. Beattie, J. Carson, W.I. Garstin Malignant neoplasms of the appendix Int J Colorectal Dis, 22 (2007), pp. 1239-1248.

\section{AUTHORS:}

1. Suresh Huchchannavar

PARTICULARS OF CONTRIBUTORS:

1. Assistant Professor, Department of Surgery, KIMS Hubli.

FINANCIAL OR OTHER COMPETING INTERESTS: None

\section{NAME ADDRESS EMAIL ID OF THE} CORRESPONDING AUTHOR:

Dr. Suresh Huchchannavar,

Assistant Professor, Department of Surgery, KIMS Hubli, Vidya Nagar,

Hubli-580020,

Karnataka.

E-mail: sureshnh72@gmail.com

Date of Submission: 14/02/2015.

Date of Peer Review: 16/02/2015.

Date of Acceptance: 23/02/2015.

Date of Publishing: 05/03/2015. 